\title{
Supplementation with rumen-protected methionine or choline during the transition period influences whole-blood immune response in periparturient dairy cows
}

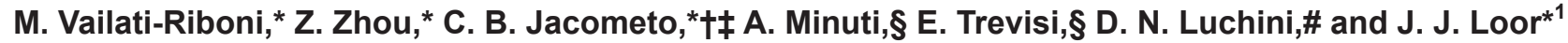 \\ *Mammalian NutriPhysioGenomics, Department of Animal Sciences and Division of Nutritional Sciences, University of Illinois, Urbana 61801 \\ †Programa de Zootecnia, Facultad de Ciencias Agropecuarias, Universidad de La Salle, 110231, Bogotá DC, Colombia \\ ¥NUPEEC, Departamento de Clínicas Veterinária, Programa de Pós-Graduação em Biotecnologia, Universidade Federal de Pelotas, 96010-900, \\ Pelotas, RS, Brazil \\ §Istituto di Zootecnica, Facoltà di Scienze Agrarie, Alimentari e Ambientali, Università Cattolica del Sacro Cuore, 29122, Piacenza, Italy \\ \#Adisseo NA, Alpharetta, GA 30022
}

\begin{abstract}
Methionine, together with Lys, is the most limiting AA for milk production in dairy cows. Besides its crucial role in milk production, Met and its derivate metabolites (e.g., glutathione, taurine, polyamines) are well-known immunonutrients in nonruminants, helping support and boost immune function and activity. In the present study, the effects of Met or choline, as its precursor, were investigated using an ex vivo whole blood challenge. The study involved 33 multiparous Holstein cows (from a larger cohort with a factorial arrangement of treatments) assigned from $\mathrm{d}-21$ to +30 relative to parturition to a basal control $(\mathrm{CON})$ diet, $\mathrm{CON}$ plus rumen-protected Met (MET, Smartamine M, Adisseo NA, Alpharetta, GA) at a rate of $0.08 \%$ of dry matter, or CON plus rumen-protected choline (CHOL, ReaShure, Balchem Inc., New Hampton, NY) at 60 $\mathrm{g} / \mathrm{d}$. Blood was sampled on d $-15,-7,2,7$, and 20 for ex vivo lipopolysaccharide (LPS) challenge, and on d $1,4,14$, and 28 relative to parturition for phagocytosis and oxidative burst assays. The MET cows had greater energy-corrected milk production and milk protein content. Overall, IL-6 response to LPS increased around parturition, whereas IL- $1 \beta$ remained constant, casting doubt on the existence of systemic immunosuppression in the peripartal period. Supplementation with MET dampened the postpartal blood response to LPS (lower IL-1 $\beta$ ), while improving postpartum neutrophil and monocyte phagocytosis capacity and oxidative burst activity. In contrast, CHOL supplementation increased monocyte phagocytosis capacity. Overall, the data revealed a peripartal immune hyper-response, which appeared to have been mitigated by MET supplemen-
\end{abstract}

Received August 1, 2016.

Accepted January 29, 2017.

${ }^{1}$ Corresponding author: jloor@illinois.edu tation. Both MET and CHOL effectively improved immune function; however, MET affected the immune and antioxidant status before parturition, which might have been beneficial to prepare the cow to respond to metabolic challenges after parturition. These results provide insights on potential differences in the immunomodulatory action of methionine and choline in dairy cows. As such, the effects observed could have implications for ration formulation and dietary strategies.

Key words: nutrition, methyl donors, transition cow, immune response

\section{INTRODUCTION}

A successful transition to lactation sets the stage for a profitable lactation, with optimal production, reproduction, and health, avoiding premature culling. Metabolic disorders and health problems are common during this time and can easily erase the entire profit potential for dairy cow farms (Drackley, 1999). It is also widely accepted that around parturition cows experience a period of generalized immunosuppression (Kehrli et al., 1989; Waller, 2000). The combined outcome of immune and metabolic dysfunction during the periparturient period is a cow that might be hyposensitive and hyporesponsive to antigens, and hence, more susceptible to infectious diseases such as mastitis (Mallard et al., 1998). On the other hand, transition cows often display an overt systemic inflammatory response related to pregnancy and lactation (Bionaz et al., 2007; Sordillo et al., 2009; Trevisi et al., 2012); thus, doubts remain about the concept of immunosuppression and the immune system response (Ishikawa et al., 2004; Sander et al., 2011; Jahan et al., 2015; Trevisi et al., 2015) during the transition period.

In addition to being considered 1 of the 2 mostlimiting AA for milk production, Met itself, and several of its metabolites, display an immunonutritional role 
[i.e., they help support and boost certain activities of the immune system in humans (Grimble and Grimble, 1998; Redmond et al., 1998; Grimble, 2006; Li et al., 2007), immune-suppressed subjects (Van Brummelen and du Toit, 2007), and dairy cows (Osorio et al., 2013)]. These biologic activities led us to hypothesize that rumen-protected Met (MET, directly or as a choline precursor) or choline (CHOL; directly or as a precursor of Met) supplementation would not only improve production performance, but also benefit the innate immune system.

To address our hypothesis, a subset of cows from Zhou et al. (2016b) that were fed a control, MET, or CHOL diet were used to determine whole blood inflammatory response to a LPS challenge (Jahan et al., 2015). The ex vivo whole blood assay (WBA) was chosen because of its advantages over in vitro or in vivo studies: (1) it is less time consuming, (2) as opposed to in vitro studies it includes nonmanipulated leukocytes, which tend to become activated by handling during extraction (Desch et al., 1989; Allen et al., 1992), (3) it allows repeated challenges as opposed to in vivo studies, and (4) the leukocytes remain in their natural environment, which means that the cellular response is influenced by the concentration of other immunological components (cytokines, receptors), hormones, and metabolites that are present in the blood sample at a given time (Røntved et al., 2005; Sordillo and Raphael, 2013).

\section{MATERIALS AND METHODS}

\section{Experimental Design and Dietary Treatments}

All procedures were approved by the Institutional Animal Care and Use Committee of the University of Illinois (protocol no. 13023). Complete details of the experimental design and animal management have been reported previously (Zhou et al., 2016b). Briefly, the experiment was conducted as a randomized complete block design with $2 \times 2$ factorial arrangement of MET (Smartamine M, Adisseo NA, Alpharetta, GA) and CHOL (ReaShure, Balchem Inc., New Hampton, NY) dietary inclusion level (with or without). Cows were blocked according to parity, previous lactation milk yield, and expected calving date. Eighty-one Holstein cows were enrolled and assigned to a basal control $(\mathbf{C O N}) \operatorname{diet}(\mathrm{n}=20)$ with no MET or CHOL supplementation; CON plus Smartamine M (MET, $\mathrm{n}=21$ ) at a rate of $0.08 \%$ of DM; CON plus ReaShure (CHOL, $\mathrm{n}=20)$ at $60 \mathrm{~g} / \mathrm{d}$; or CON plus Smartamine M and ReaShure (mixed, $\mathrm{n}=20$ ). Dosage of MET was based on Osorio et al. (2013), whereas CHOL was supplied following manufacturer's recommendations. The MET supplementation provided on average 8.0 and $12.0 \mathrm{~g} / \mathrm{d}$ of DL-methionine pre- and postpartum, respectively. The CHOL provided $12.4 \mathrm{~g} / \mathrm{d}$ of choline chloride both pre- and postpartum. All cows received the same far-off $\operatorname{diet}(1.40 \mathrm{Mcal} / \mathrm{kg}$ of DM, $10.2 \% \mathrm{RDP}$, and $4.1 \% \mathrm{RUP})$ from -50 to $-22 \mathrm{~d}$ before expected calving, close-up $\operatorname{diet}(1.52 \mathrm{Mcal} / \mathrm{kg}$ of DM, 9.1\% RDP, and $5.4 \% \mathrm{RUP})$ from $-21 \mathrm{~d}$ to expected calving, and lactation diet from calving (1.71 Mcal $/ \mathrm{kg}$ of DM, 9.7\% RDP, and 7.5\% RUP) through 30 DIM. Both supplements were topdressed from $-21 \pm 2$ to 30 DIM once daily at the AM feeding using approximately $50 \mathrm{~g}$ of ground corn as the carrier for all treatments. Supplementation of Smartamine M $(0.08 \%$ DM of TMR offered) was calculated daily for each cow. At the beginning of the close-up period, cows had an average BW of $742 \pm 81,771 \pm 81$, and $787 \pm 71 \mathrm{~kg}( \pm \mathrm{SD})$, and an average BCS of 3.53 $\pm 0.43,3.51 \pm 0.35$, and $3.49 \pm 0.42$, for CON, MET, and CHOL, respectively. For the LPS challenge, Institutional Animal Care and Use Committee approval was secured for a subset of 33 multiparous cows (11 cows per group) from the randomized complete block design study of Zhou et al. (2016a,b) in the CON, MET, and CHOL experimental groups. The selected animals were clinically healthy and free from pathogen-related inflammatory events (e.g., mastitis, metritis) throughout the whole transition period. Because fundamental data about the individual effect of Met and choline on whole blood immune response are not available in the literature, we focused exclusively on the cows fed MET or CHOL. Thus, cows in the mixed group (MET+CHOL) were not used for the current analysis.

\section{Whole Blood Assay}

LPS Challenge. The inflammatory response of blood immune cells was tested using the approach previously described by Jahan et al. (2015), with modifications. Blood was sampled before the morning feeding from the coccygeal vein on $\mathrm{d}-15$ and $-7( \pm 2)$ relative to the expected calving date, and on $\mathrm{d} 2,7$, and 20 $( \pm 1)$ relative to the actual calving date. Samples were collected into evacuated tubes (BD Vacutainer, Becton Dickinson and Company, Franklin Lakes, NJ) containing lithium heparin as anticoagulant, and placed in water at $38^{\circ} \mathrm{C}$ in a thermo-insulated container. Blood was rapidly transported to the laboratory so the challenge could be started within 30 min from sampling. Lyophilized LPS (Escherichia coli O111:B4, Sigma-Aldrich, St. Louis, MO) was prepared by dilution in Dulbecco's modified Eagle medium (Sigma-Aldrich) to obtain 2 solutions containing 0.5 and $250 \mu \mathrm{g}$ of LPS $/ \mathrm{mL}$. These solutions were aliquoted, to avoid multiple thawing and freezing, and stored at $-20^{\circ} \mathrm{C}$ until use. Three aliquots of $980 \mu \mathrm{L}$ of blood from each cow were stimulated, in 
duplicate, under a laminar airflow cabinet with $20 \mu \mathrm{L}$ of Dulbecco's modified Eagle medium (negative control sample), solutions containing 250 or $0.5 \mu \mathrm{g}$ of LPS $/ \mathrm{mL}$. Consequently, the final experimental doses were 0 (control), 0.01 (low dose), and $5 \mu \mathrm{g}$ of LPS $/ \mathrm{mL}$ of blood (high dose). The low dose represents a more physiologic challenge, whereas the high dose was used to analyze the full potential of the immune response. Samples were then incubated in a water bath at $38^{\circ} \mathrm{C}$ for $3.5 \mathrm{~h}$ at a horizontal shaking speed of 30 times/min. After incubation, plasma was harvested by centrifugation $(8,700$ $\times g$ for $16 \mathrm{~min}$ at $6^{\circ} \mathrm{C}$ ) and stored at $-80^{\circ} \mathrm{C}$. Environmental contamination with exogenous endotoxins was prevented by using certified endotoxin-free materials.

Plasma was analyzed for IL-1 $\beta$ and IL-6, myeloperoxidase (MPO), and glucose. Cytokines were analyzed via ELISA (IL-1 $\beta$ catalog no. ESS0027, IL-6 catalog no. ESS0029; Pierce, Thermo Scientific), whereas glucose was assessed in a clinical auto-analyzer (ILAB 650, Instrumentation Laboratory, Lexington, MA) using a commercial kit (catalog no. 0018250840) from Instrumentation Laboratory (Milano, Italy), as previously described (Jacometo et al., 2015). The apparent consumption of glucose $(\Delta \mathbf{G l u})$ during the challenge was estimated as the difference between glucose concentration in the unchallenged sample and the challenged sample (independently at both doses of LPS). The MPO concentration was also determined with the ILAB 650, using self-prepared reagents, following the protocol described by Bradley et al. (1982).

Phagocytosis Capacity and Oxidative Burst Activity. The simultaneous phagocytosis capacity and oxidative burst activity of peripheral monocytes and neutrophils were determined upon challenge with enteropathogenic bacteria (E. coli O118:H8; kindly donated by M. A. Ballou, Texas Tech University, Lubbock) as described by Hulbert et al. (2011) with modifications. The complete procedure can be found elsewhere (Zhou et al., 2016a). Briefly, blood was sampled on d 1, 4, 14, and 28 relative to calving into evacuated tubes (BD Vacutainer; Becton Dickinson and Company, Franklin Lakes, NJ) containing lithium heparin, and placed on ice until the assay was started. Two hundred microliters of whole blood with $40 \mu \mathrm{L}$ of $100 \mu M$ dihydrorhodamine 123 (Sigma-Aldrich, St. Louis, MO), and $40 \mu \mathrm{L}$ of propidium iodine-labeled bacteria $(109 \mathrm{cfu} / \mathrm{mL}$; Hulbert et al., 2011) were incubated at $38.5^{\circ} \mathrm{C}$ for $10 \mathrm{~min}$. After red blood cells were lysed with ice-cold MilliQ water, cells were resuspended in PBS solution. Subsequently, monocytes were marked with APC anti-CD14 antibody (catalog no. 301808, Biolegend, San Diego, CA) and neutrophils were stained with CH138A primary antibovine granulocyte monoclonal antibody (catalog no. BOV2067, Washington State University, Pullman) and
PE-labeled secondary antibody (catalog no. 1020-09S, Southern Biotech, Birmingham, AL). Lastly, the cells were re-suspended in PBS solution for flow cytometry analyses (LSR II, Becton Dickinson, San Jose, CA). Data are reported as percentages of CD14/CH138A positive cells with phagocytosis and oxidative burst capability.

\section{Statistical Analysis}

Data derived from the LPS challenge (cytokines, MPO, glucose, $\Delta \mathrm{Glu}$ ) were subjected to ANOVA and analyzed by stage of parturition (pre or post) using repeated measures ANOVA with PROC MIXED. The statistical model included time $(\mathbf{T})$, diet $(\mathbf{D} ; \mathrm{CON}$, MET, CHOL), LPS $(\mathbf{L})$, and their interaction $(\mathrm{T} \times$ $\mathrm{D}, \mathrm{T} \times \mathrm{L}, \mathrm{D} \times \mathrm{L}, \mathrm{T} \times \mathrm{D} \times \mathrm{L})$ as fixed effects. Phagocytosis capacity and oxidative burst activity were also subjected to ANOVA using repeated measures ANOVA with PROC MIXED, including time (T), diet (D; $\mathrm{CON}, \mathrm{MET}, \mathrm{CHOL})$, and their interaction $(\mathrm{T} \times \mathrm{D})$ as fixed effects. For both analyses, cow nested within treatment was the random effect. The KR statement was used for computing the denominator degrees of freedom, whereas Spatial Power was used as the covariance structure, as it best fitted the data compared with Compound Symmetry. To reduce the probability of type I error, the Tukey-Kramer adjustment (using the adjusted degrees of freedom from the KR statement) was implemented. Data were considered significant at a $P \leq 0.05$, and tendencies were considered at a $P \leq 0.10$.

\section{RESULTS}

\section{LPS Challenge}

Prepartum level of IL-1 $\beta$ remained constant $(\mathrm{T}, P$ $=0.80)$, whereas IL-6 concentration increased $(\mathrm{D}, P$ $<0.05)$ from -15 to -7 DIM. In contrast, postpartum both cytokines were affected by time (IL-1 $\beta, P=0.07$; IL-6, $P<0.01$; Table 1 ). The IL-6 concentration had a sustained decrease from 2 to 20 DIM, whereas IL-1 $\beta$ concentration peaked $(P<0.05)$ at 7 DIM and then decreased $(P<0.05)$ to an intermediate level at 20 DIM. Stimulation with LPS significantly affected (L, $P$ $<0.01$ ) concentration of IL- $1 \beta$ and IL- 6 , both pre- and postpartum, which directly correlated with the levels of LPS (e.g., greater LPS administration was followed by greater cytokine concentration; Table 1 ). The only exception was IL- 6 concentration at -15 d prepartum, where both LPS concentrations (0.01 and 5) induced a similar $(\mathrm{L} \times \mathrm{T}, P=0.96)$ response (Figure 1$)$. No effect of diet was detected prepartum for both cytokines, 
whereas a tendency was detected for IL-1 $\beta$ postpartum $(P=0.07)$, as MET had lower $(P<0.05)$ concentration compared with $\mathrm{CON}$, but not with $\mathrm{CHOL}$, which displayed an intermediate level compared with other groups. This was due mainly to the IL- $1 \beta$ response to the high $(5 \mu \mathrm{g} / \mathrm{mL})$ dose of LPS $(\mathrm{D} \times \mathrm{L}, P<0.01)$, which had similar statistical differences among groups, whereas at the low dose only numerical differences were evident (Figure 2).

Neither dietary supplementation nor challenge with LPS had an effect on MPO concentration (Table 1), despite both MET and CHOL having numerically greater concentrations than CON. Time instead had an overall effect (T, $P<0.01)$ on MPO concentration both pre- and postpartum. Prepartum MPO concentration increased $(P<0.05)$ from -15 to -7 DIM, whereas postpartum it peaked at 2 DIM, and then decreased $(P$ $<0.05)$ to stable levels at 7 and 20 DIM.

Overall glucose concentration was not affected by time, either pre- or postpartum, whereas it was affected by challenge with LPS (L, $P<0.01$ ), both pre- and postpartum (Table 1). Glucose concentration was higher $(P<0.05)$ at $0 \mu \mathrm{g}$ of LPS $/ \mathrm{mL}$ of blood, when compared with both 0.01 and $5 \mu \mathrm{g}$ of $\mathrm{LPS} / \mathrm{mL}$. No differences (both pre- and postpartum, $P=0.89$ ) were detected when comparing the 2 doses (0.01 vs. $5 \mu \mathrm{g} /$ $\mathrm{mL}$ ). No main effect of diet was detected for glucose (Table 1). A significant $\mathrm{D} \times \mathrm{T}$ interaction $(P=0.03)$ prepartum was detected; however, no differences were detected among dietary groups within each time point, or among time points within each dietary group.

Prepartum, no effect of diet, time, LPS, or their interactions was detected for glucose consumption $(\Delta$ Glu; D, T, L, D $\times \mathrm{T}, \mathrm{D} \times \mathrm{L}, \mathrm{L} \times \mathrm{T}, \mathrm{D} \times \mathrm{T} \times \mathrm{L}, P$ $>0.05$; Table 1). In contrast, postpartum significance was detected for time $(\mathrm{T}, P<0.01)$ and its interaction with diet $(\mathrm{D} \times \mathrm{T}, P=0.02)$. Time-wise, overall $\Delta$ Glu had a sustained decrease $(P<0.05)$ from 2 to 20 DIM; however, differences were detected among dietary groups $(\mathrm{D} \times \mathrm{T})$. In $\mathrm{CON}$ cows it remained constant postpartum, whereas in MET cows $\Delta$ Glu decreased to 0 at 20 DIM $(P<0.05)$ after holding unchanged at 2 and 7 DIM. In CHOL cows it peaked at 2 DIM $(P<$ $0.05)$, and then decreased $(P<0.05)$ to a lower and sustained level at 7 and 20 DIM. Despite the different time progression within dietary groups, no differences among groups were detected at any time point postpartum.

\section{Phagocytosis Capacity and Oxidative Burst Activity}

Regarding the percentage of phagocytic cells, diet had an effect on neutrophils $(\mathrm{D}, P=0.03)$ and a tendency on monocytes $(\mathrm{D}, P=0.07$; Figure 3$)$. In neutrophils,

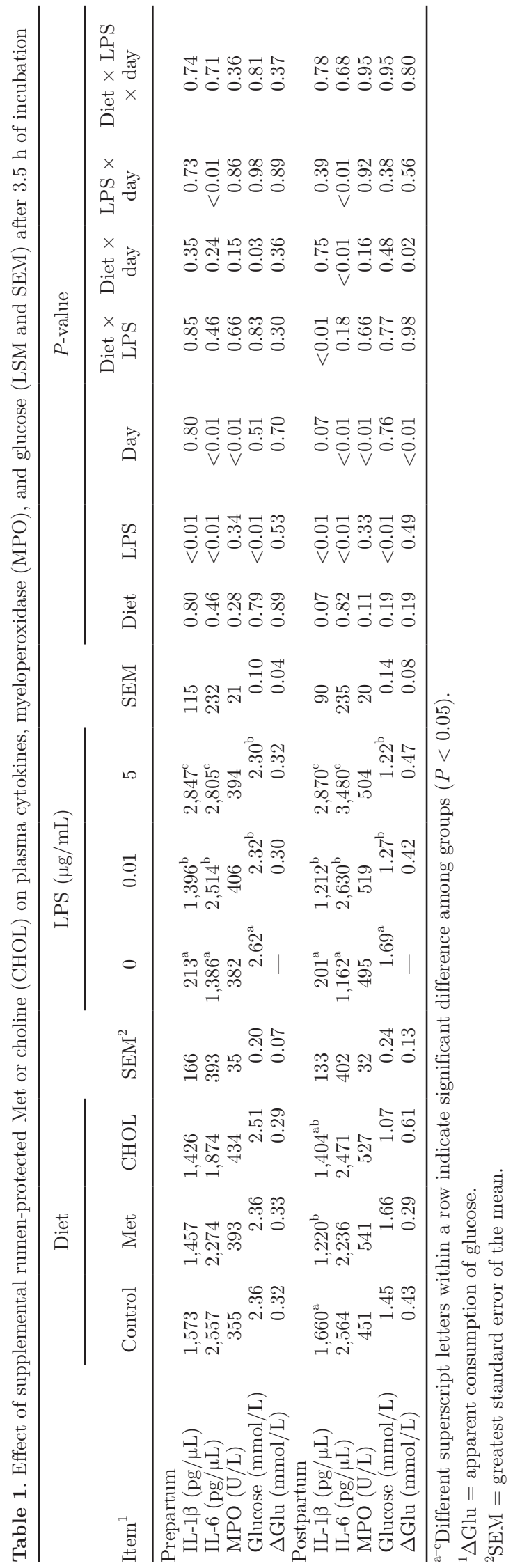

Journal of Dairy Science Vol. 100 No. 5, 2017 
compared with CON, feeding MET led to greater $(P$ $<0.05$ ) percentage of phagocytic cells, whereas CHOL led to an intermediate level that was not different from other groups (CHOL vs. CON, $P=0.64$; CHOL vs. MET, $P=0.17)$. In monocytes, instead, no differences were detected among groups (CON vs. MET, $P=0.17$; $\mathrm{CON}$ vs. $\mathrm{CHOL}, P=0.09$; MET vs. $\mathrm{CHOL}, P=0.98)$. Supplementing either MET or CHOL increased $(P<$ 0.05) the percentage of cells performing an oxidative burst in monocytes (D, $P<0.01$ ), whereas for neutrophils $(\mathrm{D}, P<0.01)$ only MET had greater $(P<$ 0.05 ) values than $\mathrm{CON}$, with CHOL at an intermediate level between the 2 groups (CHOL vs. CON, $P=0.06$; CHOL vs. MET, $P=0.57$; Figure 3 ).

Overall, time had no effect on monocyte phagocytosis capacity $(\mathrm{T}, P=0.43 ; \mathrm{D} \times \mathrm{T}, P=0.31)$ and monocyte $(\mathrm{T}, P=0.92 ; \mathrm{D} \times \mathrm{T}, P=0.54)$ and neutrophil $(\mathrm{T}, P$ $=0.70 ; \mathrm{D} \times \mathrm{T}, P=0.43)$ oxidative burst activity. Instead, neutrophil phagocytosis capacity was significant due to time (T, $P=0.05$ ), but no significant differences were detected between time points (Figure 4).

\section{DISCUSSION}

The objective of the present study was to evaluate the effect of supplemental rumen-protected methionine or choline during the periparturient period on ex vivo whole blood immune response. The cows used were a subset of a larger cohort in a $2 \times 2$ factorial arrangement of MET and CHOL (Zhou et al., 2016b), from which we omitted the group receiving both supplements. This was done to specifically study the effect of each methyl donor without introducing further variation due to the combination of the 2 supplements. During ex vivo stimulation of whole blood with LPS, we chose 2 different concentrations: 0.01 and $5 \mu \mathrm{g} / \mathrm{mL}$. Despite LPS being often undetectable in plasma, as it is quickly cleared out of the organism to prevent systemic inflammatory responses (Hewett and Roth, 1993; Gegner et al., 1995; Satoh et al., 2008), our lowest concentration $(0.01 \mu \mathrm{g} / \mathrm{mL})$ lies within physiological ranges detectable in healthy or clinical animals (Dohmen et al., 2000; Dosogne et al., 2002). The higher dose of LPS (5 $\mu \mathrm{g} /$

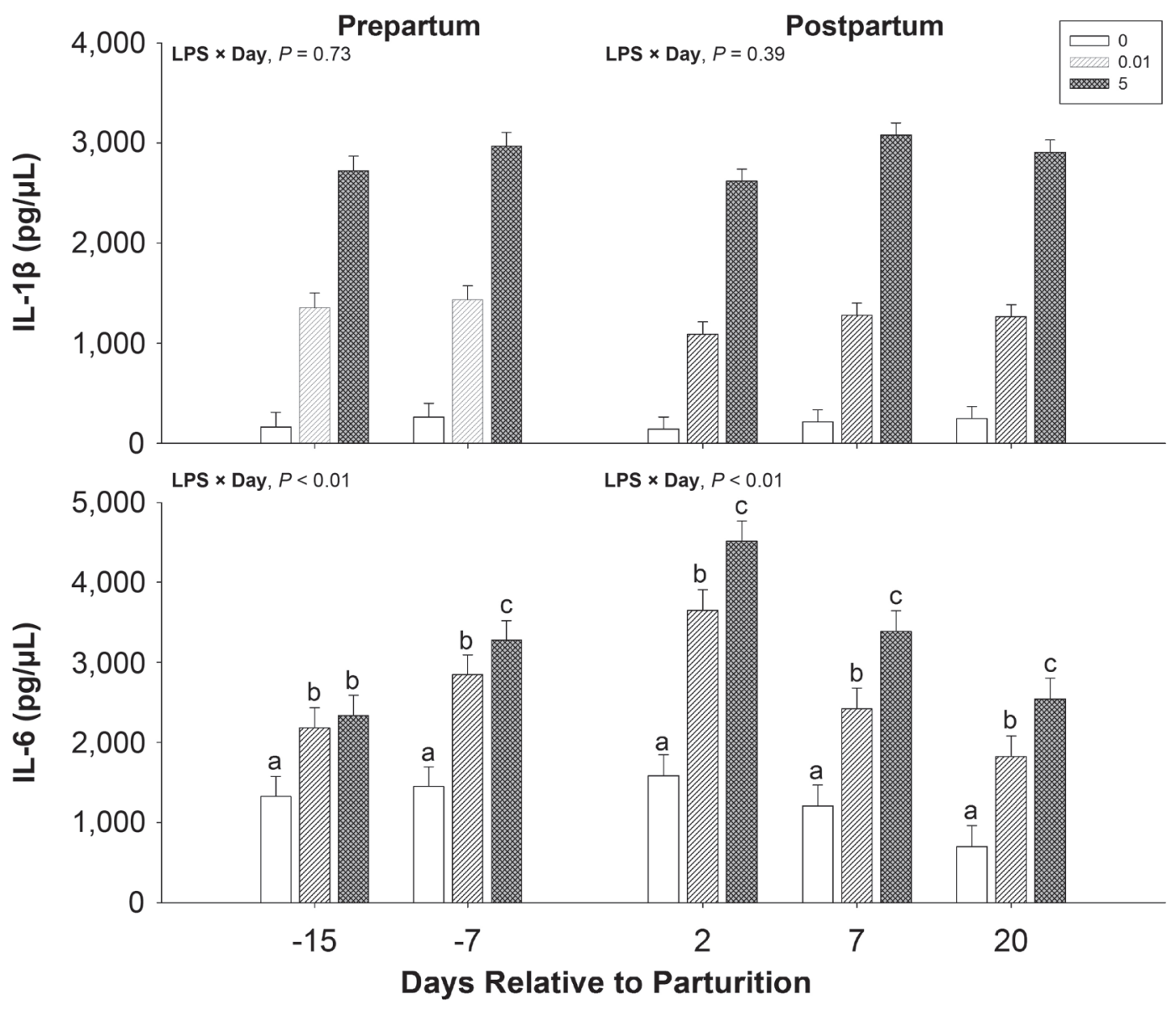

Figure 1. Plasma concentration of IL-1 $\beta$ and IL-6 in Holstein cows during the transition period after a 3.5-h incubation of whole blood with $0,0.01$, and $5 \mu \mathrm{g}$ of LPS $/ \mathrm{mL}$ of blood. Different letters denote statistical differences $(P \leq 0.05)$ among LPS doses within each time point. Error bars represent SEM associated with the model estimate. 
$\mathrm{mL}$ ) was chosen to record the maximum immunological response when the immune system is stimulated to its full extent.

\section{Immunomodulatory Effect of Methionine and Choline}

Immunosuppression during the transition period has long been regarded as a major reason for the increased susceptibility of dairy cows to infections (Mallard et al., 1998; Sander et al., 2011). However, data from recent studies have raised doubts on the actual existence of peripartal impairment of immune function, at least at a systemic level (Ishikawa et al., 2004; Sander et al., 2011). Because the enrolled cows remained clinically healthy throughout the transition period, limiting any immune-related confounding factor, our current results support the latter hypothesis and agree with LPS challenge results obtained by Jahan et al. (2015) where no depression of the immune response was observed; rather, the immune response to LPS was greater at
-3 and $3 \mathrm{~d}$ around parturition (Jahan et al., 2015). However, contrary to Jahan et al. (2015), the pattern of IL-6 response differed from that of IL-1 $\beta$ (Figure 1). This could be attributed to numerous differences in diet, management practices, and cow genetics (Italian vs. American Holstein genetics) between the 2 studies. Whereas LPS elicited an increasing response in release of IL- 6 at -15 through 2 DIM followed by a subsequent decrease in response by 20 DIM, the IL- $1 \beta$ response to LPS was constant throughout the transition period. Furthermore, except at -15 DIM, the increase in dose of LPS resulted in greater IL- 6 and IL-1 $\beta$ production. That response was similar to Jahan et al. (2015) where a higher LPS dose did not induce a significant increase in IL-6 response.

This chronological trend in the cytokine response, together with the lack of time effect on immune cell functionality (Figure 4), is in conflict with the dogma that cows experience immunosuppression during the transition into lactation (Kehrli et al., 1989; Mallard

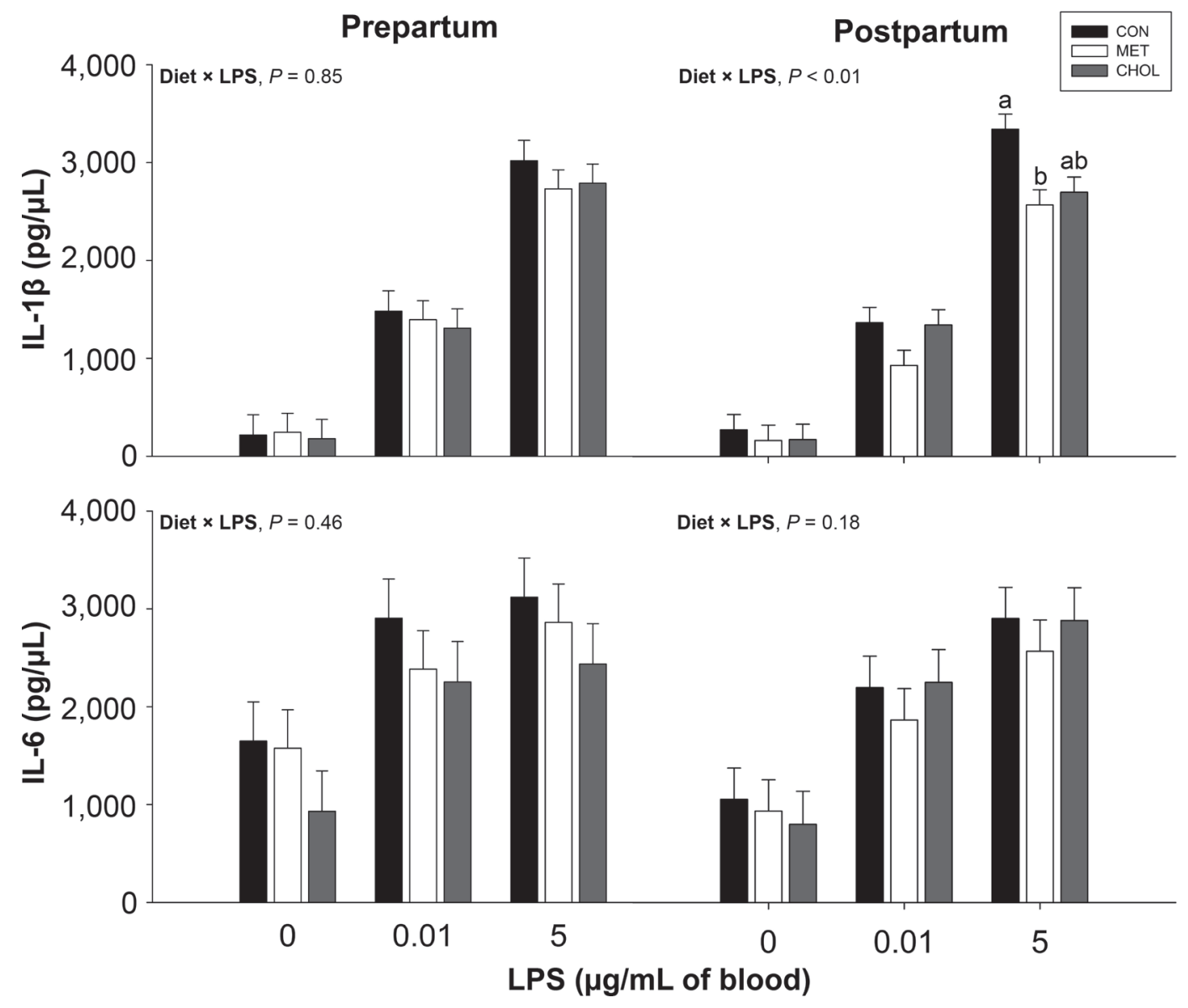

Figure 2. Effects of supplementing multiparous Holstein cows during the peripartal period with rumen-protected methionine (MET; Smartamine M, Adisseo NA, Alpharetta, GA) or rumen-protected choline (CHOL; ReaShure, Balchem Inc., New Hampton, NY) on plasma cytokine concentration after a 3.5-h incubation of whole blood with $0,0.01$, and $5 \mu \mathrm{g}$ of LPS $/ \mathrm{mL}$ of blood. Different letters denote statistical differences $(P \leq 0.05)$ among dietary groups within each LPS dose. CON $=$ control. Error bars represent SEM associated with the model estimate. 
et al., 1998; Hoeben et al., 2000). Not only they contradict that dogma, but agree with previous studies where immune function did not decrease around parturition nor throughout the whole transition period (Meglia et al., 2005; Loiselle et al., 2009; Sander et al., 2011). As discussed by Sander et al. (2011), most of the studies using immune cell functional assays have been conducted with blood-extracted or purified leukocyte preparations. Rarely, ex vivo WBA, as in the present study, are used (Meglia et al., 2005; Sander et al., 2011; Jahan et al., 2015). The advantage of WBA is that immune function depends not only on the intrinsic capability of the cells of an animal, but also on the presence and concentration of immuno-stimulant molecules, like opsonizing factors, which increase cell phagocytosis activity (Trowbridge and Emling, 1993). Thus, the values
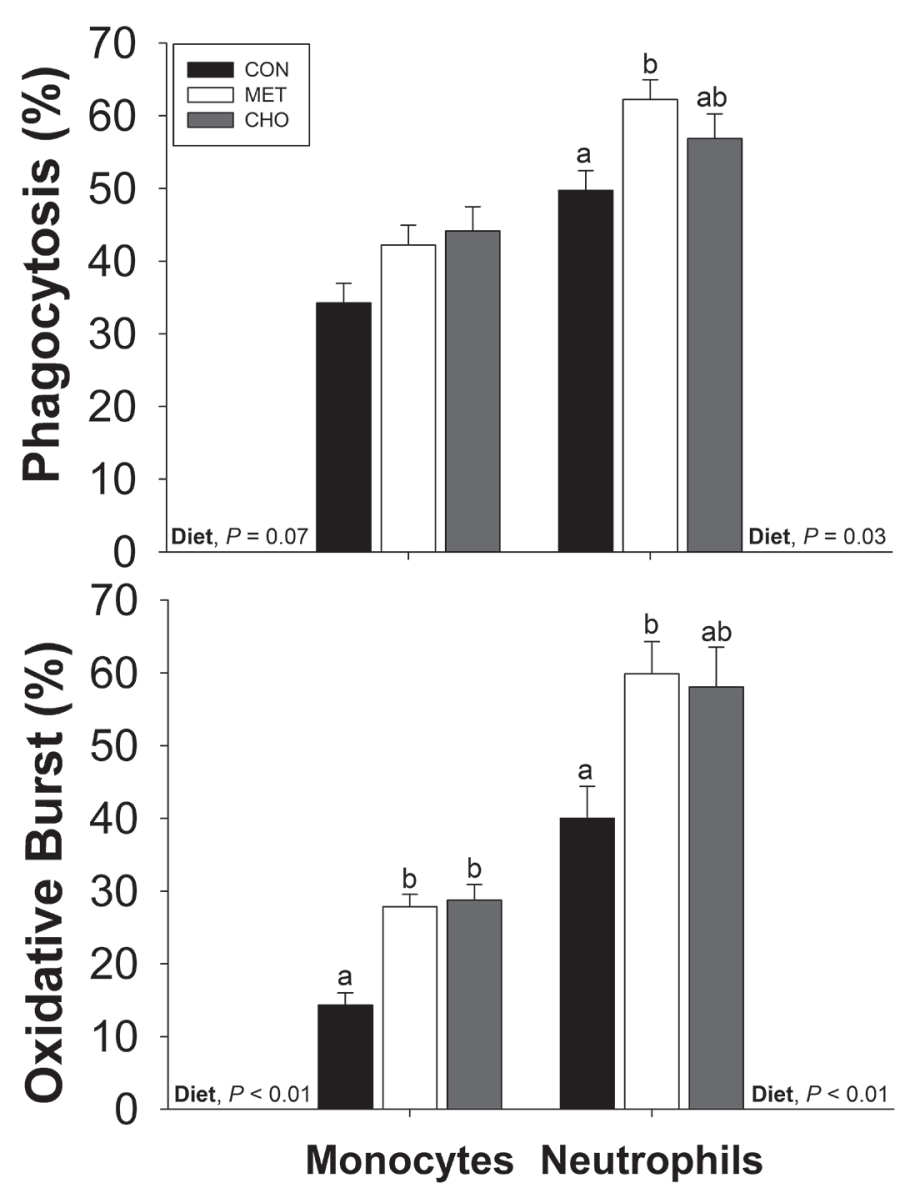

Figure 3. Effects of supplementing multiparous Holstein cows during the peripartal period with rumen-protected methionine (MET; Smartamine M, Adisseo NA, Alpharetta, GA) or rumen-protected choline (CHOL; ReaShure, Balchem Inc., New Hampton, NY) on overall postpartal phagocytosis activity and oxidative burst capacity of bovine blood monocytes and neutrophils. Different letters denote statistical differences $(P \leq 0.05)$ among dietary groups within each cell type. $\mathrm{CON}=$ control. Error bars represent SEM associated with the model estimate. obtained with WBA reflect more closely the immune capability of the animal (Sander et al., 2011).

Our results, together with previous studies (Sordillo et al., 1995; Røntved et al., 2005; Sander et al., 2011; Jahan et al., 2015), further contradict the previous hypothesis that cows may be hypo-sensitive and hypo-responsive to antigens (Mallard et al., 1998), underscoring the high reactivity of blood immune cells (e.g., leukocytes) around calving. Previous research in humans led to the hypothesis that an environment promoting oxidative stress could have repercussions on both the innate and the adaptive immune response, as it may facilitate the binding of pathogens or antigens to effector cells leading to a hyper-responsive innate immune system (Piganelli et al., 2002; Crapo, 2003). Because it is well known that transition cows experience a certain degree of oxidative stress (Trevisi et al., 2009; Sordillo and Raphael, 2013), due to their characteristic metabolic shift (Drackley, 1999), the presence of oxidants could be an important cause of the observed hyper-response. Thus, whatever the pro-inflammatory stimuli [endogenous (e.g., cytokines) or exogenous (e.g., bacteria cell wall components)] in this period could lead to an excessive response that might be detrimental to the cow. For instance, higher prepartal concentrations of IL- 6 and IL-1 $\beta$ were, in fact, associated with some degree of failure of dairy cows to transition (Ishikawa et al., 2004; Trevisi et al., 2012, 2015). Furthermore, the anorexigenic (Plata-Salaman, 1998, 2001; Wong and Pinkney, 2004) and metabolic effect (Lagathu et al., 2006; Yang et al., 2008; Pallares et al., 2010; De Matteis et al., 2016) of these cytokines means that their systemic increase could impair the normal adaptation to lactation.

In light of the above considerations, because Met is the source of glutathione and taurine, 2 of the most important cellular antioxidants (Pompella et al., 2003; Shimada et al., 2015), and it was shown to improve the oxidative status of periparturient cows when fed in rumen-protected form (Osorio et al., 2014a,b), supplementing Met in the peripartal period appears to be a feasible way to avoid a detrimental response of the immune system. This is surmised by the lower overall postpartum concentration of IL-1 $\beta$ (Table 1) in MET than $\mathrm{CON}$ cows because of a reduction in sensitivity to LPS (Figure 2). Similar numerical results were obtained for IL-6, but the higher variability in responses precluded differences from reaching statistical significance (Table 1, Figure 2). Together with greater phagocytosis capacity in neutrophils, and oxidative burst activity of both neutrophils and monocytes (Figure 3), these results indicate that Met supplementation dampened the innate immune response to an inflammatory stimulus while enhancing its functional activity. A functional 


\section{Monocytes}
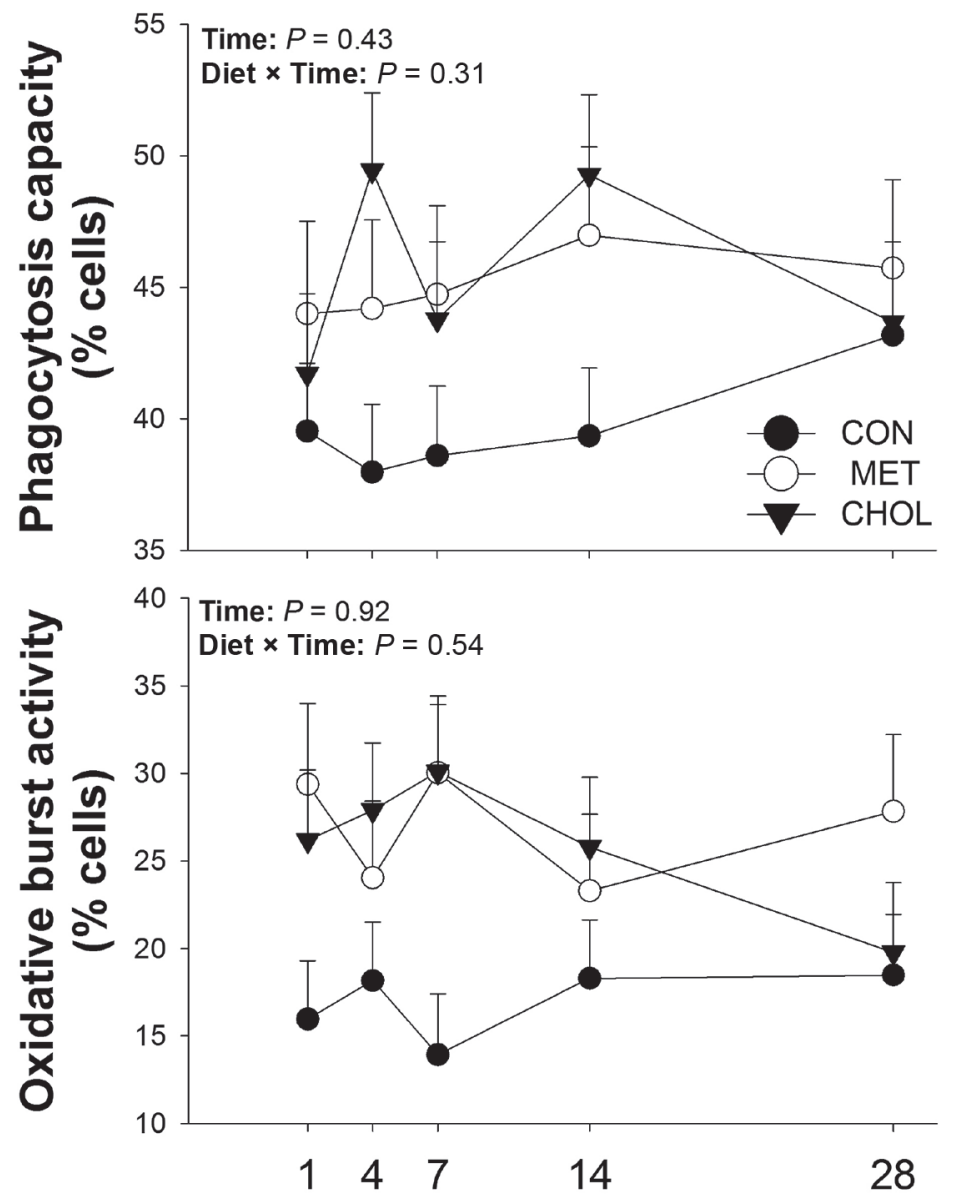

Neutrophils

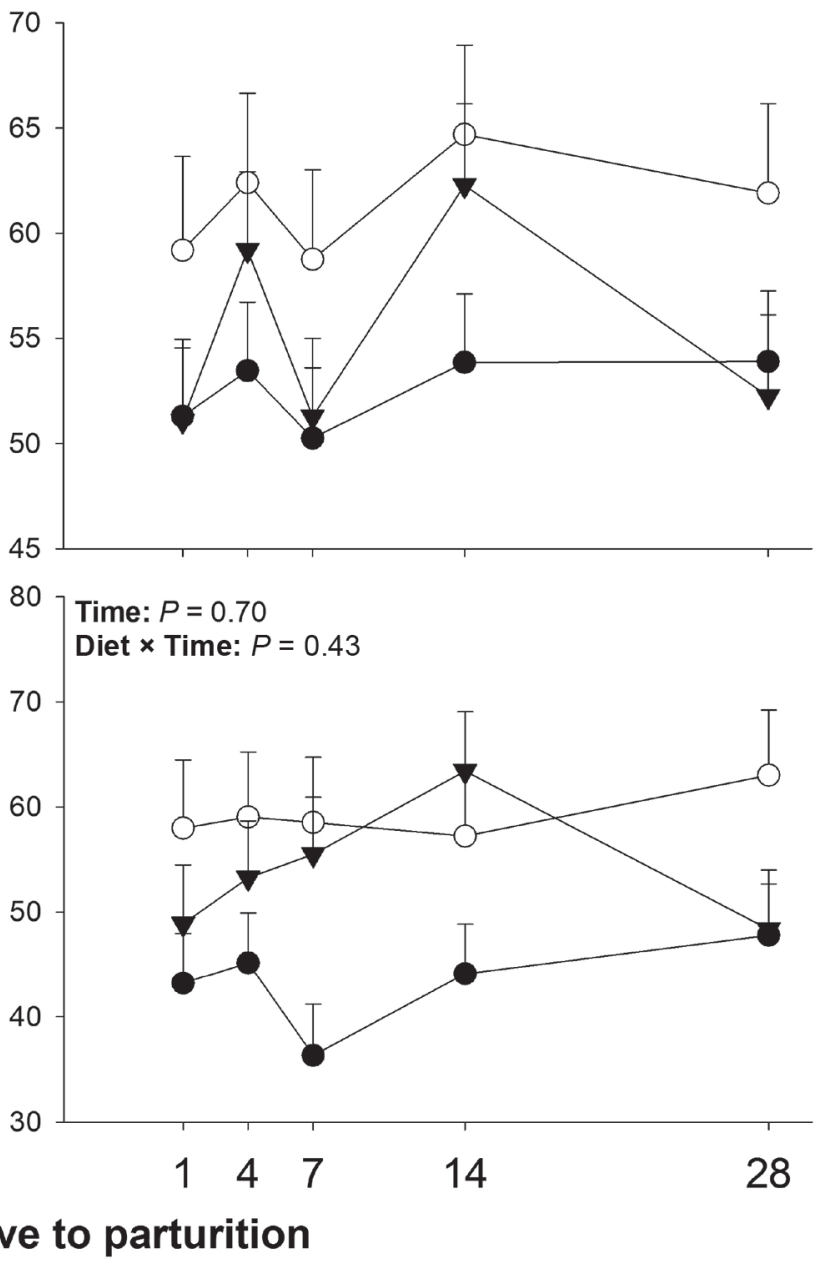

Figure 4. Effects of supplementing multiparous Holstein cows during the peripartal period with rumen-protected methionine (MET; Smartamine M, Adisseo NA, Alpharetta, GA) or rumen-protected choline (CHOL; ReaShure, Balchem Inc., New Hampton, NY) on postpartal phagocytosis activity and oxidative burst capacity of bovine blood monocytes and neutrophils over time. CON $=$ control. Error bars represent SEM associated with the model estimate.

enhancement of the leukocyte activity also was previously observed in transition dairy cows fed Smartamine M (Osorio et al., 2013). Despite not reaching statistical significance, the postpartal concentration of MPO in MET cows (Table 1), independent of LPS stimulation dose, helps reinforce this hypothesis.

Cows supplemented Met displayed other positive consequences at a systemic level [e.g., hepatic concentrations of glutathione and reduced glutathione were greatly increased compared with CHOL-supplemented cows (Zhou et al., 2016a)]. In addition, despite similar concentrations of reactive oxygen species and ferric reducing ability of plasma (Zhou et al., 2016a), they had greater circulating concentrations of paraoxonase and albumin, together with lower levels of haptoglobin
(Zhou et al., 2016a), all of which indicated better liver function, a lower inflammatory state, and possibly a greater antioxidant protection (Turk et al., 2005; Bionaz et al., 2007).

The phenotypic consequences of the immune modulation can be seen in the pre- and postpartum DMI and greater production performance in cows supplemented with methionine (Zhou et al., 2016b), indicating that a more controlled immune response could be one factor contributing to the Met-driven improvement of lactation. Similarly, supplementation of choline also stimulated some aspects of immune function (Figure $3)$. However, when compared with the control group, choline failed to dampen the whole-blood inflammatory response. Compared with $\mathrm{CON}$, this was mirrored by 
the numerical difference in postpartum MPO concentration (Table 1) and neutrophil phagocytosis capacity and oxidative burst (Figure 3). Phenotypically, no improvement in DMI or milk performance was detected with choline (Zhou et al., 2016b) despite previous studies reporting beneficial effects of rumen-protected choline on production (Piepenbrink and Overton, 2003; Elek et al., 2008).

As discussed above, Met is an important source of the antioxidants glutathione and taurine (Pompella et al., 2003; Shimada et al., 2015). Taurine, which is the most abundant free AA in neutrophil cytosol, can act as a trap for hypochlorous acid, forming the long-lived, less reactive, and less toxic oxidant taurine monochloramine (Tau-Cl; Marcinkiewicz, 1997). Both in humans and mice, Tau-Cl had an anti-inflammatory effect by reducing cytokine production of stimulated neutrophils and monocytes (Marcinkiewicz et al., 1998; Chorazy et al., 2002). Despite the lack of statistically significant differences in MPO, as MET induced greater oxidative burst in both neutrophils and monocytes it is possible that there was greater formation of Tau-Cl, further supporting a mechanism through which Met may mitigate immune cell peripartal hyper-responsiveness.

The lack of control of the hyper-response by immune cells during supplementation of choline could instead be explained by the more direct action of Met. For instance, supplementation of rumen-protected Met was directly linked with an increase in its concentration in the circulation (Papas et al., 1984; Blum et al., 1999), but no studies have been published (to our knowledge) demonstrating the efficacy of supplemental choline for increasing circulating concentrations of Met or its derivate antioxidants. Furthermore, immune cells lack the ability to convert choline into Met through the betaine pathway, which in mammals (Finkelstein et al., 1972; Szegedi et al., 2008), and bovine specifically (Lambert et al., 2002), is present only in the liver and kidney.

Despite supplemental rumen-protected Met and choline inducing different responses to LPS, their effect on oxidative burst was similar (Figure 3). Multiple studies have been conducted in nonruminants on the modulatory effects of these 2 nutrients on the immune system. For instance, Met-derived cysteine, glutathione, and polyamines improved proliferation and function of lymphocytes and leukocytes (Li et al., 2007). Choline, through phosphatidic acid and second messenger molecules (lysophosphatidic acid and 1,2-diacylglycerol), was demonstrated to modulate respiratory burst in neutrophil phagocytes by regulating the assembly of the NADPH oxidase (Forman and Torres, 2001). Thus, because leukocytes seem unable to use methionine or choline interchangeably, our results indicate a comple- mentary relationship between the 2 molecules on leukocyte function.

\section{Energy Consumption and Efficiency of the Immune Response}

At least in nonruminants, glucose is a main energy substrate for leukocytes during an inflammatory response (Beck and Valentine, 1953; Stjernholm et al., 1972). A similar response could be proposed in the present study because of the lower glucose concentration upon challenge with 0.01 or $5 \mu \mathrm{g}$ of LPS $/ \mathrm{mL}$ of blood compared with controls. The reduction, however, was not dose dependent (Table 1). Dietary supplementation was able to alter the apparent glucose consumption by the immune system over time, but no differences were detected at each time point among the groups. Because modulating energy costs of the immune response is possible and used as a feasible pharmacologic target in humans (Delmastro-Greenwood and Piganelli, 2013), further research is needed to better understand the role of both Met and choline in the regulation of immune cell energy metabolism.

\section{CONCLUSIONS}

The current data support the growing body of evidence indicating that cows do not undergo a period of immunosuppression, at least at a systemic level, during the transition period. Conversely, cows experience a systemic hyper-response around parturition, probably linked to oxidative stress phenomena. Methionine supplementation, but not choline, in rumen-protected form, was able to dampen this hyper-response, probably acting on the oxidative status of the animal, or indirectly through its immunologically active metabolites (e.g., taurine). Supplementation with Met also increased immune cell antimicrobial functions. These results provide novel insights on the immunomodulatory differences and the timing for how Met and choline affect the cow during the peripartum period. These data shed light on the applicability of 2 key dietary methyl donors in dairy cow ration formulation and dietary strategies around parturition.

\section{ACKNOWLEDGMENTS}

This research was partially supported by Adisseo (Commentry, France).

\section{REFERENCES}

Allen, J. N., D. J. Herzyk, E. D. Allen, and M. D. Wewers. 1992. Human whole blood interleukin-1-beta production: kinetics, cell 
source, and comparison with TNF-alpha. J. Lab. Clin. Med. 119:538-546.

Beck, W. S., and W. N. Valentine. 1953. The carbohydrate metabolism of leukocytes: A review. Cancer Res. 13:309-317.

Bionaz, M., E. Trevisi, L. Calamari, F. Librandi, A. Ferrari, and G. Bertoni. 2007. Plasma paraoxonase, health, inflammatory conditions, and liver function in transition dairy cows. J. Dairy Sci. 90:1740-1750.

Blum, J. W., R. M. Bruckmaier, and F. Jans. 1999. Rumen-protected methionine fed to dairy cows: Bioavailability and effects on plasma amino acid pattern and plasma metabolite and insulin concentrations. J. Dairy Sci. 82:1991-1998.

Bradley, P. P., D. A. Priebat, R. D. Christensen, and G. Rothstein 1982. Measurement of cutaneous inflammation: Estimation of neutrophil content with an enzyme marker. J. Invest. Dermatol. 78:206-209.

Chorazy, M., E. Kontny, J. Marcinkiewicz, and W. Maslinski. 2002. Taurine chloramine modulates cytokine production by human peripheral blood mononuclear cells. Amino Acids 23:407-413.

Crapo, J. D. 2003. Oxidative stress as an initiator of cytokine release and cell damage. Eur. Respir. J. 44(Suppl.):4s-6s.

De Matteis, L., G. Bertoni, R. Lombardelli, O. Wellnitz, H. A. Van Dorland, M. C. Vernay, R. M. Bruckmaier, and E. Trevisi. 2016. Acute phase response in lactating dairy cows during hyperinsulinemic hypoglycaemic and hyperinsulinemic euglycaemic clamps and after intramammary LPS challenge. J. Anim. Physiol. Anim. Nutr. (Berl.).https://doi.org/10.1111/jpn.12463.

Delmastro-Greenwood, M. M., and J. D. Piganelli. 2013. Changing the energy of an immune response. Am. J. Clin. Exp. Immunol. $2: 30-54$.

Desch, C. E., N. L. Kovach, W. Present, C. Broyles, and J. M. Harlan. 1989. Production of human tumor necrosis factor from whole blood ex vivo. Lymphokine Res. 8:141-146.

Dohmen, M. J., K. Joop, A. Sturk, P. E. Bols, and J. A. Lohuis. 2000. Relationship between intra-uterine bacterial contamination, endotoxin levels and the development of endometritis in postpartum cows with dystocia or retained placenta. Theriogenology 54:10191032 .

Dosogne, H., E. Meyer, A. Sturk, J. van Loon, A. M. Massart-Leen, and C. Burvenich. 2002. Effect of enrofloxacin treatment on plasma endotoxin during bovine Escherichia coli mastitis. Inflamm. Res. 51:201-205.

Drackley, J. K. 1999. ADSA Foundation Scholar Award. Biology of dairy cows during the transition period: The final frontier? J. Dairy Sci. 82:2259-2273.

Elek, P., J. R. Newbold, T. Gaal, L. Wagner, and F. Husveth. 2008. Effects of rumen-protected choline supplementation on milk production and choline supply of periparturient dairy cows. Animal $2: 1595-1601$

Finkelstein, J. D., B. J. Harris, and W. E. Kyle. 1972. Methionine metabolism in mammals: Kinetic study of betaine-homocysteine methyltransferase. Arch. Biochem. Biophys. 153:320-324.

Forman, H. J., and M. Torres. 2001. Signaling by the respiratory burst in macrophages. IUBMB Life 51:365-371.

Gegner, J. A., R. J. Ulevitch, and P. S. Tobias. 1995. Lipopolysaccharide (LPS) signal transduction and clearance. Dual roles for LPS binding protein and membrane CD14. J. Biol. Chem. 270:53205325 .

Grimble, R. F. 2006. The effects of sulfur amino acid intake on immune function in humans. J. Nutr. 136(Suppl.):1660S-1665S

Grimble, R. F., and G. K. Grimble. 1998. Immunonutrition: Role of sulfur amino acids, related amino acids, and polyamines. Nutrition $14: 605-610$

Hewett, J. A., and R. A. Roth. 1993. Hepatic and extrahepatic pathobiology of bacterial lipopolysaccharides. Pharmacol. Rev. 45:382411.

Hoeben, D., E. Monfardini, G. Opsomer, C. Burvenich, H. Dosogne, A. De Kruif, and J. F. Beckers. 2000. Chemiluminescence of bovine polymorphonuclear leucocytes during the periparturient pe- riod and relation with metabolic markers and bovine pregnancyassociated glycoprotein. J. Dairy Res. 67:249-259.

Hulbert, L. E., J. A. Carroll, N. C. Burdick, R. D. Randel, M. S. Brown, and M. A. Ballou. 2011. Innate immune responses of temperamental and calm cattle after transportation. Vet. Immunol. Immunopathol. 143:66-74.

Ishikawa, Y., K. Nakada, K. Hagiwara, R. Kirisawa, H. Iwai, M. Moriyoshi, and Y. Sawamukai. 2004. Changes in interleukin-6 concentration in peripheral blood of pre- and post-partum dairy cattle and its relationship to postpartum reproductive diseases. J. Vet. Med. Sci. 66:1403-1408.

Jacometo, C. B., J. S. Osorio, M. Socha, M. N. Correa, F. PiccioliCappelli, E. Trevisi, and J. J. Loor. 2015. Maternal consumption of organic trace minerals alters calf systemic and neutrophil mRNA and microRNA indicators of inflammation and oxidative stress. J. Dairy Sci. 98:7717-7729.

Jahan, N., A. Minuti, and E. Trevisi. 2015. Assessment of immune response in periparturient dairy cows using ex vivo whole blood stimulation assay with lipopolysaccharides and carrageenan skin test. Vet. Immunol. Immunopathol. 165:119-126.

Kehrli, M. E. Jr., B. J. Nonnecke, and J. A. Roth. 1989. Alterations in bovine neutrophil function during the periparturient period. Am. J. Vet. Res. 50:207-214.

Lagathu, C., L. Yvan-Charvet, J. P. Bastard, M. Maachi, A. Quignard-Boulange, J. Capeau, and M. Caron. 2006. Long-term treatment with interleukin-1beta induces insulin resistance in murine and human adipocytes. Diabetologia 49:2162-2173.

Lambert, B. D., E. C. Titgemeyer, G. L. Stokka, B. M. DeBey, and C. A. Loest. 2002. Methionine supply to growing steers affects hepatic activities of methionine synthase and betaine-homocysteine methyltransferase, but not cystathionine synthase. J. Nutr. 132:2004-2009.

Li, P., Y. L. Yin, D. Li, S. W. Kim, and G. Wu. 2007. Amino acids and immune function. Br. J. Nutr. 98:237-252.

Loiselle, M. C., C. Ster, B. G. Talbot, X. Zhao, G. F. Wagner, Y. R. Boisclair, and P. Lacasse. 2009. Impact of postpartum milking frequency on the immune system and the blood metabolite concentration of dairy cows. J. Dairy Sci. 92:1900-1912.

Mallard, B. A., J. C. Dekkers, M. J. Ireland, K. E. Leslie, S. Sharif, C. L. Vankampen, L. Wagter, and B. N. Wilkie. 1998. Alteration in immune responsiveness during the peripartum period and its ramification on dairy cow and calf health. J. Dairy Sci. 81:585-595.

Marcinkiewicz, J. 1997. Neutrophil chloramines: Missing links between innate and acquired immunity. Immunol. Today 18:577-580.

Marcinkiewicz, J., A. Grabowska, J. Bereta, K. Bryniarski, and B. Nowak. 1998. Taurine chloramine down-regulates the generation of murine neutrophil inflammatory mediators. Immunopharmacology 40:27-38.

Meglia, G. E., A. Johannisson, S. Agenas, K. Holtenius, and K. P. Waller. 2005. Effects of feeding intensity during the dry period on leukocyte and lymphocyte sub-populations, neutrophil function and health in periparturient dairy cows. Vet. J. 169:376-384.

Osorio, J. S., P. Ji, J. K. Drackley, D. Luchini, and J. J. Loor. 2013. Supplemental Smartamine M or MetaSmart during the transition period benefits postpartal cow performance and blood neutrophil function. J. Dairy Sci. 96:6248-6263.

Osorio, J. S., P. Ji, J. K. Drackley, D. Luchini, and J. J. Loor. 2014a. Smartamine M and MetaSmart supplementation during the peripartal period alter hepatic expression of gene networks in 1-carbon metabolism, inflammation, oxidative stress, and the growth hormone-insulin-like growth factor 1 axis pathways. J. Dairy Sci. 97:7451-7464

Osorio, J. S., E. Trevisi, P. Ji, J. K. Drackley, D. Luchini, G. Bertoni, and J. J. Loor. 2014b. Biomarkers of inflammation, metabolism, and oxidative stress in blood, liver, and milk reveal a better immunometabolic status in peripartal cows supplemented with Smartamine M or MetaSmart. J. Dairy Sci. 97:7437-7450.

Pallares, V., A. Castell-Auvi, L. Cedo, M. Pinent, A. Ardevol, and M. Blay. 2010. A paracrine loop between adipocytes and macrophages 
in adipose tissue: An in vitro model to study obesity-induced inflammation. J. Nutrigenet. Nutrigenomics 3:96.

Papas, A. M., J. L. Vicini, J. H. Clark, and S. Peirce-Sandner. 1984. Effect of rumen-protected methionine on plasma free amino acids and production by dairy cows. J. Nutr. 114:2221-2227.

Piepenbrink, M. S., and T. R. Overton. 2003. Liver metabolism and production of cows fed increasing amounts of rumen-protected choline during the periparturient period. J. Dairy Sci. 86:1722-1733.

Piganelli, J. D., S. C. Flores, C. Cruz, J. Koepp, I. Batinic-Haberle, J. Crapo, B. Day, R. Kachadourian, R. Young, B. Bradley, and K. Haskins. 2002. A metalloporphyrin-based superoxide dismutase mimic inhibits adoptive transfer of autoimmune diabetes by a diabetogenic T-cell clone. Diabetes 51:347-355.

Plata-Salaman, C. R. 1998. Cytokines and feeding. News Physiol. Sci. 13:298-304.

Plata-Salaman, C. R. 2001. Cytokines and feeding. Int. J. Obes. Relat. Metab. Disord. 25(Suppl. 5):S48-S52.

Pompella, A., A. Visvikis, A. Paolicchi, V. De Tata, and A. F. Casini. 2003. The changing faces of glutathione, a cellular protagonist. Biochem. Pharmacol. 66:1499-1503.

Redmond, H. P., P. P. Stapleton, P. Neary, and D. Bouchier-Hayes. 1998. Immunonutrition: the role of taurine. Nutrition 14:599-604

Røntved, C. M., J. B. Andersen, J. Dernfalk, and K. L. Ingvartsen. 2005. Effects of diet energy density and milking frequency in early lactation on tumor necrosis factor-alpha responsiveness in dairy cows. Vet. Immunol. Immunopathol. 104:171-181.

Sander, A. K., M. Piechotta, G. Schlamberger, H. Bollwein, M. Kaske, A. Sipka, and H. J. Schuberth. 2011. Ex vivo phagocytic overall performance of neutrophilic granulocytes and the relation to plasma insulin-like growth factor-I concentrations in dairy cows during the transition period. J. Dairy Sci. 94:1762-1771.

Satoh, M., S. Ando, T. Shinoda, and M. Yamazaki. 2008. Clearance of bacterial lipopolysaccharides and lipid A by the liver and the role of argininosuccinate synthase. Innate Immun. 14:51-60.

Shimada, K., C. J. Jong, K. Takahashi, and S. W. Schaffer. 2015. Role of ROS production and turnover in the antioxidant activity of taurine. Adv. Exp. Med. Biol. 803:581-596.

Sordillo, L. M., G. A. Contreras, and S. L. Aitken. 2009. Metabolic factors affecting the inflammatory response of periparturient dairy cows. Anim. Health Res. Rev. 10:53-63.

Sordillo, L. M., G. M. Pighetti, and M. R. Davis. 1995. Enhanced production of bovine tumor necrosis factor-alpha during the periparturient period. Vet. Immunol. Immunopathol. 49:263-270.
Sordillo, L. M., and W. Raphael. 2013. Significance of metabolic stress, lipid mobilization, and inflammation on transition cow disorders. Vet. Clin. North Am. Food Anim. Pract. 29:267-278.

Stjernholm, R. L., C. P. Burns, and J. H. Hohnadel. 1972. Carbohydrate metabolism by leukocytes. Enzyme 13:7-31.

Szegedi, S. S., C. C. Castro, M. Koutmos, and T. A. Garrow. 2008. Betaine-homocysteine S-methyltransferase-2 is an S-methylmethionine-homocysteine methyltransferase. J. Biol. Chem. 283:89398945.

Trevisi, E., M. Amadori, A. M. Bakudila, and G. Bertoni. 2009. Metabolic changes in dairy cows induced by oral, low-dose interferonalpha treatment. J. Anim. Sci. 87:3020-3029.

Trevisi, E., M. Amadori, S. Cogrossi, E. Razzuoli, and G. Bertoni. 2012. Metabolic stress and inflammatory response in high-yielding, periparturient dairy cows. Res. Vet. Sci. 93:695-704.

Trevisi, E., N. Jahan, G. Bertoni, A. Ferrari, and A. Minuti. 2015. Pro-inflammatory cytokine profile in dairy cows: Consequences for new lactation. Ital. J. Anim. Sci. 14:3862.

Trowbridge, H. O., and R. C. Emling. 1993. Inflammation: A Review of the Process. 4th ed. Quintessence Publ. Co., Chicago, IL.

Turk, R., D. Juretic, D. Geres, N. Turk, B. Rekic, V. Simeon-Rudolf, M. Robic, and A. Svetina. 2005. Serum paraoxonase activity in dairy cows during pregnancy. Res. Vet. Sci. 79:15-18.

Van Brummelen, R., and D. du Toit. 2007. L-methionine as immune supportive supplement: A clinical evaluation. Amino Acids $33: 157-163$.

Waller, K. P. 2000. Mammary gland immunology around parturition. Influence of stress, nutrition and genetics. Adv. Exp. Med. Biol. 480:231-245.

Wong, S., and J. Pinkney. 2004. Role of cytokines in regulating feeding behaviour. Curr. Drug Targets 5:251-263.

Yang, Y., D. Ju, M. Zhang, and G. Yang. 2008. Interleukin-6 stimulates lipolysis in porcine adipocytes. Endocrine 33:261-269.

Zhou, Z., O. Bulgari, M. Vailati-Riboni, E. Trevisi, M. A. Ballou, F. C. Cardoso, D. N. Luchini, and J. J. Loor. 2016a. Rumen-protected methionine compared with rumen-protected choline improves immunometabolic status in dairy cows during the peripartal period. J. Dairy Sci. 99:8956-8969.

Zhou, Z., M. Vailati-Riboni, E. Trevisi, J. K. Drackley, D. N. Luchini, and J. J. Loor. 2016b. Better postpartal performance in dairy cows supplemented with rumen-protected methionine compared with choline during the peripartal period. J. Dairy Sci. 99:8716-8732. 